\title{
La función dialogal de la teología: condición de posibilidad para una cultura del encuentro"
}

\author{
Juan Pablo Espinosa Arce
}

Recepción: 7 de julio de 2018 • Aprobación: 25 de julio de 2018

\section{Resumen}

Este artículo reflexiona en torno a la función dialogal de la teología que comienza a asumirse como un elemento central en la teología con el Concilio Vaticano II. Será la constitución Gaudium et spes y el desarrollo teológico, magisterial y cultural inmediatamente posterior el que permitirá comprender cómo el diálogo constituye la condición de posibilidad para vivir, en términos de Francisco, una auténtica cultura del encuentro.

Palabras clave: lenguaje, cultura, teología, papa Francisco, Gaudium et spes.

* Artículo de reflexión. Citar como: Espinosa Arce, J. P. (2019). La función dialogal de la teología: condición de posibilidad para una cultura del encuentro. Albertus Magnus, X(2), 145-163. Dor: https://doi.org/10.153322/5005413.5217.

** Universidad Católica de Chile, Chile. Correo electrónico: jpespinosa@uc.cl 


\title{
The dialogical function of theology: Condition of possibility for a culture of encounter
}

\begin{abstract}
In the present article we will reflect on the dialogical function of theology that begins to be assumed as a central element in theology with the Second Vatican Council. It will be the Gaudium et spes Constitution and the theological, magisterial and cultural development immediately afterwards that will allow us to understand how dialogue constitutes the condition of possibility to live, in Francisco's terms, an authentic culture of encounter.
\end{abstract}

Keywords: language, culture, theology, Pope Francis, Gaudium et spes.

\section{A função dialógica da teologia: condição de possibilidade para uma cultura de encontro}

\section{Resumo}

Neste artigo, refletiremos sobre a função dialógica da teologia que começa a ser assumida como elemento central da teologia com o Concílio Vaticano II. A Constituição Gaudium et spes e o desenvolvimento teológico, magisterial e cultural logo a seguir nos permitirão compreender como o diálogo constitui a condição de possibilidade de viver, nos termos de Francisco, uma autêntica cultura do encontro.

Palavras-chave: língua, cultura, teologia, papa Francisco, Gaudium et spes. 
Pero convertirse en pueblo es todavía más, y requiere un proceso constante en el cual cada nueva generación se ve involucrada. Es un trabajo lento y arduo que exige querer integrarse y aprender a hacerlo hasta desarrollar una cultura del encuentro en una pluriforme armonía.

Francisco

\section{Introducción}

La tesis de nuestra propuesta se articula a partir de dos categorías: diálogo y cultura del encuentro. Sin diálogo no se provoca el encuentro como "pluriforme armonía" (Francisco, 2013, n. 220). Por ello, hemos calificado al primero de condición de posibilidad. Gracias al diálogo se genera el acercamiento entre las personas, entre las experiencias de vida, entre las comprensiones de mundo y entre las formas de estar en la sociedad. Hay en el diálogo una forma de transmisión de la propia vida en cuanto permite que nos convirtamos en pueblo, en comunidad, en generación, pero no a la manera de la uniformidad, sino en clave de unidad en la diferencia, más cercana al poliedro - utilizando la imagen de Francisco- que a la de esfera. ${ }^{1}$ Hay construcción social, política, teológica y cultural desde el diálogo y el encuentro. Gracias a estas categorías pasamos de la confrontación a la convivencia y al entendimiento. La empatía y la búsqueda de respuestas a los grandes interrogantes de la vida humana pasan, necesariamente, por compartir dialógicamente otras formas de comprensión.

A efectos metodológicos de esta propuesta, se realizará el siguiente recorrido: en primer lugar, comprender cómo el diálogo es, ante todo, una cuestión antropológica en tanto el ser humano es el animal que dialoga y que la misma

1 Francisco piensa en el poliedro en dos niveles: una acentuación ecuménica y una cuestión de evangelización urbana. La segunda es la que nos interesa. En Evangelii gaudium, recuerda que "no hay que olvidar que la ciudad es un ámbito multicultural" (2013, n. 74). Y más adelante, en ese mismo número, sostiene: "En las grandes urbes puede observarse un entramado en el que grupos humanos comparten las mismas formas de soñar la vida y similares imaginarios y se constituyen en nuevos sectores humanos, en territorios culturales, en ciudades invisibles. Varias formas culturales conviven de hecho, pero ejercen prácticas de segregación y de violencia. La Iglesia está llamada a ser servidora de un difícil diálogo". El diálogo al que está llamada la Iglesia, no por su propia iniciativa sino porque Dios mismo ha dialogado con el ser humano, el mundo y la historia, debe realizarse considerando esta multiplicidad de rostros, expresiones y experiencias humanas y religiosas. Por ello, Scannone (2017) afirma que, gracias a esta cultura del encuentro en el diálogo, "el pueblo fiel de Dios puede perfeccionar su rostro multiforme [...] en un espacio sociocultural, como es el de la ciudad. El fecundo encuentro entre ellas y sus respectivos imaginarios puede ser ilustrado con la imagen del poliedro"' (p. 251). 
realidad está construida lingüísticamente; en segundo lugar, y porque el diálogo es una cuestión antropológica, Dios asume el diálogo como forma de autocomunicarse y encontrarse con el ser humano. Comprenderemos, por tanto, la dimensión teológica del diálogo tanto en la revelación misma como en la disciplina teológica, dimensión que surge de la primera. En esta misma dimensión teológica, revisar cómo el Concilio Vaticano II asume el diálogo como nueva actitud, sensibilidad, incluso como signo de los tiempos. Con el Concilio, comenzamos a cruzar un nuevo tiempo eclesial impreso con el diálogo. Finalmente, comprender cómo Evangelii gaudium y la cultura del encuentro constituye un caso particular de recepción de este espíritu del diálogo en la Iglesia, sobre todo en el diálogo social como espacio de construcción de la paz con énfasis en el diálogo social en su relación con la cuestión de la libertad religiosa.

\section{El diálogo: cuestión antropológica}

Una de las cualidades del ser humano es la capacidad de dialogar. Por el diálogo entablamos relaciones, conocemos el mundo, nos reconocemos como miembros de una comunidad humana mayor. Es, en definitiva, el medio de socialización primario. Y por ello sostiene Asensio (2004):

Pocas cualidades podrían considerarse más definitorias del ser humano que la de su capacidad para utilizar señales lingüísticas como medio de comunicación. Somos, en efecto, los únicos narradores de la vida y de lo que en ella acontece, la única especie que emplea palabras para producir mensajes con los que coordinar acciones y compartir todo tipo de vivencias, conocimientos y deseos. (p. 69)

Los animales no humanos no pueden expresar palabras codificadas para darse a entender y para manifestar sus sentimientos, emociones o experiencias. Con esto, a su vez, se genera el desafío de comprender cómo estas mismas experiencias que se transmiten a través del habla, de lo fonético, de la lengua, han sido centrales en este tiempo. No se puede reducir todo a la teoría, sino que también hay que repensar nuestras prácticas y cómo hemos de verbalizar o manifestar corporalmente esas mismas prácticas. Por ende, el diálogo está entendido como una cuestión del lenguaje y también como una interpretación del lenguaje, lo que se llama hermenéutica. Decimos algo e interpretamos lo que decimos y lo que otros dicen.

Es más: nuestra época está marcada filosófica, sociológica, teológica y culturalmente por el signo del lenguaje. A propósito de esto, Ramírez (2015) 
recuerda que el siglo XXI puede ser calificado de la época del giro lingüístico, en que el lenguaje aparece como "uno de los temas preferidos y más abordados por los pensadores contemporáneos" (p. 302). Por ello, es necesario tener una adecuada comprensión de este fenómeno auténticamente humano. En esto Benjamin (1991) habla acerca del "lenguaje en general y sobre el lenguaje de los humanos" (p. 59). Se puede hablar, incluso, del mito de creación por la palabra. Algunas de sus conclusiones son:

Toda expresión de la vida espiritual del hombre puede concebirse como una especie de lenguaje [...] cada comunicación de contenidos espirituales es lenguaje, y la comunicación por medio de la palabra es solo un caso particular del lenguaje humano, de su fundamento o de aquello que sobre él se funda, como ser la justicia o la poesía. (p. 59).

Cuando Benjamin habla de "vida espiritual", está pensando, en primer lugar, en la tradición judía de la que él es parte. Pero también podemos ampliar el concepto de lo espiritual a la comunicación de realidades que salen de nosotros para ir a otro. Eso ya es diálogo. Junto con ello, el reconocimiento de que existen otras formas de lenguaje: poesía o justicia. Hay un lenguaje que va más allá del significado original y que amplía su sentido, como son las metáforas poéticas y las cuestiones jurídicas, ambas unidas por la comunicación por medio de la palabra.

En segundo lugar, la comprensión de que existe una participación de las cosas en un llamado "lenguaje en general". Todo tiene una naturaleza lingüística. Y por ello Benjamin (1991) se pregunta “¿qué comunica el lenguaje?” (p. 60), a lo que el filósofo responde que el lenguaje "comunica su correspondiente entidad o naturaleza espiritual. Es fundamental entender que dicha entidad espiritual se comunica en el lenguaje y no por medio del lenguaje" (p. 60). Por ello, concluye que las cosas poseen "una entidad lingüística de las cosas y la más clara manifestación de ello es el lenguaje mismo" (p. 61).

Luego, Benjamin (1991) vuelve a preguntarse sobre la forma en la que el hombre se comunica, a lo que responde:

El hombre es el nombrador; en eso reconocemos que desde él habla el lenguaje puro. Toda naturaleza, en la medida en que se comunica, se comunica en el lenguaje y por ende, en última instancia, en el hombre. Por ello es el señor de la naturaleza y puede nombrar a las cosas [...] en este sentido, el hombre es el portavoz del lenguaje, el único, porque habla en el nombre. El nombre no solo es la proclamación última, es además la llamada propia del lenguaje. (p. 63) 
Por ello, podríamos concluir que en la ontología del ser humano se encuentra el signo del lenguaje y la capacidad para el diálogo. Hay un poder creador en la palabra, sobre todo en nombrar las cosas. El nombre revela una identidad y es capaz de narrar una multiplicidad de sentidos de expresión vivencial. Hay una expresión y también una recepción del lenguaje. Y también hay un sentido comunitario del lenguaje, en cuanto el lenguaje compartido, eso es el diálogo, permite la sociabilidad y, por ende, aparece el diálogo como expresión de un sentirse miembros de una colectividad con identidad y pertenencia.

De esta articulación social del lenguaje, escribe Maturana (1999):

El lenguaje es un modo de vivir juntos en el flujo de las coordinaciones recurrentes de conductas consensuales y es nuestra vida en lenguaje como el tipo particular de primates bípedos que somos, lo que nos torna humanos. (p. 188)

Con ello, para Maturana (1999), los seres humanos somos gracias al lenguaje que pronunciamos y que nos une con otros seres humanos con los que compartimos códigos comunes y pactos simbólicos que nacen como acuerdos sociales. Finalmente, el lenguaje es eso: pacto social, posibilidad de encontrarnos y crear historia. Es más: la misma realidad está construida lingüísticamente en el flujo constante de lo dicho e interpretado. El lenguaje comienza en la infancia, ${ }^{2}$ donde "aprendemos a emplear lenguaje usualmente a través del habla, pero también de otros modos como por medio de señas de cuerpo y manos en el caso de la sordera" (p. 44). Y a medida que avanzamos en el desarrollo psíquico, social y corporal, vamos aumentando nuestros niveles de expresividad. Aprendemos a usar el lenguaje, en palabras de Maturana. Y cuando aprendemos a usar el lenguaje, se provoca el sentido de cohesión que le es propio. En sus palabras:

Creamos con otros diferentes modos de vida juntos según los diferentes hechos en los que participamos y llegamos a ser en nuestros cuerpos según el empleo del lenguaje en el cual crecemos. Como resultado,

2 Sostiene Asensio (2003): "La apertura a lo humano se produce, en cada recién nacido, a partir de la constante interacción comunicativa que este establece, ya desde su nacimiento, con las personas que lo acogen. Los bebés llegan al mundo provistos de unas capacidades de significación que les permiten, a través de distintas señales no verbales (olores, contactos piel a piel, sonrisas, miradas, gestos, sonidos, etc.) comunicarse con sus congéneres, establecer con ellos un diálogo progresivo de intercambio de miradas, de contactos corporales y de sonidos, a partir del cual el recién nacido experimenta un sentimiento de aceptación y acogida que resulta imprescindible para su sano desarrollo. La importancia de esta comunicación no lingüística en la formación del vínculo madre-hijo y para las relaciones humanas en general ha sido sobradamente puesta de manifiesto por la Etología, la Psicología evolutiva y la Antropología" (p. 73). 
cuando adultos creamos el mundo que vivimos como una expansión adicional del mundo que creamos cuando niños. (p. 44)

Por lo anterior, se termina por reconocer la dimensión evolutiva, psicológica, neuronal y corporal del mismo lenguaje y del diálogo. Estamos antropológicamente capacitados para esto. Lo anterior implica que la realidad es construida a través del lenguaje. El lenguaje crea realidad. Importa el cómo uno dice las cosas, en qué contexto las expresa y a quién. Hay entonces una fenomenología del diálogo en cuanto el diálogo es un fenómeno humano. Por ello, Heidegger (2000) sostuvo que el lenguaje es la casa del ser. En sus palabras:

Antes de hablar, el hombre debe dejarse interpelar de nuevo por el ser, con el peligro de que, bajo este reclamo, él tenga poco o raras veces algo que decir. Solo así se vuelve a regalar a la palabra el valor precioso de su esencia y al hombre la morada donde habitar en la verdad del ser. (pp. 4-5)

La habitabilidad en la casa del lenguaje tiene que ver con nuestra esencia humana, ya que las palabras permiten que nos comprendamos como personas, es decir, como seres en relación. Sin las palabras y el encuentro con los otros (sentido de cohesión del lenguaje), nos sentimos solos. Por ello, "privarnos de ella (de la relación lingüística) equivale a negar nuestro valor como personas, nuestra propia existencia" (Asensio, 2003, p. 88). Y con mayor sentido la experiencia, ya que, y como sostiene este autor,

en la medida en que las personas dan sentido a sus vidas y relaciones relatando su experiencia, no pueden evitar sentir un profundo malestar cuando se las priva de contar esos relatos o bien consideran que estos no han sido bien interpretados por quienes los escuchan. (p. 88)

\section{El diálogo: una cuestión teológica}

\subsection{En cuanto a la revelación}

Si el ser humano está configurado esencialmente por el signo del lenguaje y de la capacidad para encontrarse con otros a través del diálogo, a partir de la fe en la revelación comprendemos que Dios ha sido el que ha creado al ser humano como capacitado para encontrarse y dialogar con otros, consigo mismo y con el 
mismo Creador. Con ello, afirmamos que la razón última de la presencia del diálogo como condición de posibilidad de una cultura del encuentro está en el hecho de que Dios mismo ha entablado el diálogo de salvación con la humanidad. Por esta comprensión la teología fundamental prefiere hablar más de autocomunicación que de revelación. Mientras que la segunda categoría se ha comprendido en uno tono más jurídico, como la declaración de principios, la categoría de autocomunicación involucra la identidad personal de Dios que libremente ha querido salir al encuentro del ser humano, ${ }^{3}$ categoría fuertemente influida por "el paradigma de la teoría de la comunicación [...] con las categorías básicas: acontecimiento, persona, encuentro y comunicación" (Müller, 2009, p. 46).

Dios es Palabra (cfr. Jn 1, 1) que se dice desde los comienzos de la historia tanto en la creación del mundo (cfr. Gn 1, 2) como en la historia de Abraham y del nacimiento de Israel (cfr. Gn 12, 1). Dios es el que es capaz de entablar relaciones de amistad con Moisés con quien dialoga como con un amigo (cfr. Ex 33,11 ) y que al final de los tiempos (cfr. Heb 1, 1-2) dialoga con el ser humano en Jesucristo, Palabra-diálogo hecha carne (cfr. Jn 1, 14). Por tanto, es necesario comprender cómo el diálogo tiene una fuerte raigambre histórica, antropológica y cristológica. Dios, por lo anterior, utiliza categorías y formas de revelación que el ser humano puede comprender. Esto recibe el nombre de condescendencia divina. Por ende, si antropológicamente el diálogo es una de las formas básicas de encontrarse, Dios mismo dialoga con el ser humano a fin de encontrarse. Así, para el cristianismo, la forma paradigmática de una cultura del encuentro está en el encuentro originario entre Dios y el ser humano. Y, por ello, "es evidente que no es posible intentar hablar de Dios sin estar atentos a las reglas que fija el lenguaje humano" (Ramírez, 2015, p. 302). El uso lingüístico de nuestra humanidad responde a una lógica creadora de Dios en cuanto llamada y respuesta, diálogo y testimonio, encuentro y amor.

3 Müller (2009), a propósito de este cambio de categorías, sostiene que "bajo el influjo de una reciente filosofía de la libertad (superadora del dualismo sujeto-objeto), y recurriendo a las nuevas categorías de lo personal, dialogal, social e histórico, el II Concilio Vaticano ha entendido la revelación sobre todo desde el punto de vista de la 'autocomunicación de Dios como verdad y vida'. Hay aquí una cierta corrección de la concepción intelectualista de la fe, en especial de la cultivada por la teología de la controversia postridentina, que ponía el acento en la obediencia a las proposiciones doctrinales vinculantes del magisterio" (p. 47). Con ello, acontece la comprensión de que en la autocomunicación de Dios al hombre se manifiestan dos perspectivas íntimamente unidas: la profesión de fe en un conjunto de verdades reveladas, pero también el encuentro dialógico (la fe) entre Dios y el ser humano. Waldenfels (1994), a propósito del cambio de paradigma, sobre todo con la categoría del encuentro, recuerda que "la categoría de encuentro [...] sugiere a su vez el carácter multilateral de las relaciones interpersonales y de su proceso. Lleva a preguntar por la estructura del encuentro" (p. 225). 
El Dios que es totalmente Otro ha querido libremente presentarse ante el ser humano como un Tú con el que quiere dialogar. En palabras de Ramírez (2015), "lo incondicional, lo extraordinario e inabarcable podía irrumpir en nuestro mundo con toda su fuerza, incluso, estando sometido a las condiciones del lenguaje y de la historia" (p. 305). Esto es, en definitiva, el fundamento de la cultura del encuentro: Israel se constituye como Pueblo en virtud de la llamada de Dios. La Iglesia vive su fe en cuanto encuentro con un acontecimiento, Jesucristo, que constituye nuestro horizonte de sentido (cfr. Benedicto XVI, 2005, n. 1). La Iglesia, consciente de su vocación dialógica, debe vivir en el mundo a partir del diálogo y del encuentro, situación que no ha sido obvia en varios momentos de su historia, pero que con el Vaticano II se asumió como una sensibilidad imprescindible.

\subsection{En cuanto a la misma disciplina teológica}

Por ser una sensibilidad teológica, comprendemos:

Es en el lenguaje, y no en otro lugar, donde Dios se revela y realiza su acción salvadora en toda su novedad, y con toda su fuerza transformadora. Todo lo que aparece en el mundo como acontecimiento revelador está sujeto al lenguaje, que no solo se expresa o comunica, sino [que] se realiza, tal como aparece atestiguado innumerables veces en la misma escritura. (Ramírez, 2015, p. 308)

Dios co-habita entre nosotros en el signo del diálogo. Esta co-habitación, que se asume en la experiencia de fe y que busca la comprensión, es actualizada y celebrada a través de la disciplina teológica. En la comprensión teológica actual, sobre todo en la teología fundamental, la cuestión del diálogo constituye una novedosa sensibilidad que busca poner al cristianismo en el espacio público, en medio de la pluriforme realidad de expresiones de sentido. El paso de la apologética a la teología fundamental así lo significa y realiza.

Autores como Geffré (1969) reconocen que la apologética ha estado presente a lo largo de la historia de la Iglesia. Desde la tradicional recomendación de Pedro de "dar razón de la esperanza" (1 P 3, 15), hasta los intentos de pensar la apologética como ciencia objetiva del siglo XVIII (que se extiende hasta los albores del Vaticano II), la defensa de la fe ha sido un elemento común en el cristianismo. La apologética tradicional, sostiene Geffré, se desarrolla a partir de "los signos externos, las profecías, los milagros sobre todo, que deben demostrar con evidencia el hecho de que Dios se ha revelado" (p. 340). Aquí la apologética nace desde la urgencia de justificar racionalmente el hecho de la revelación frente 
a los racionalistas y los reformados de la misma catolicidad. Tres elementos son claves en esta demostratio: lo religioso marcado por la justificación de la existencia de Dios y de la religión, lo cristiano en cuanto defensa del cristianismo como verdadera religión y la demostración católica en la búsqueda de comprender que la verdadera Iglesia es la Iglesia católica romana.

Este proyecto apologético fracasa a comienzos del siglo $X X$, sobre todo porque

uno de los grandes límites de la apologética como ciencia objetiva es concebir la credibilidad como una nota común a todos los dogmas antes de haber emprendido una reflexión teológica y crítica sobre el dogma más fundamental, a saber, la revelación misma. (Geffré, 1969, p. 342)

Aquí la urgencia que surge es la necesidad de recuperar el aspecto crítico de la misma teología, y en especial la necesidad de pensar cómo la credibilidad del dogma del Dios revelado impacta concretamente la experiencia viva del creyente. Por ello, la teología propone hablar de autocomunicación de Dios más que de revelación. De esta manera, y como sugiere Geffré (1969),

cuando se trata de un valor como la religión, el juicio de credibilidad no puede ser puramente racional. Depende de una libre elección existencial o, al menos, de un juicio ético fundamental. Justificar la fe es decantar el sentido del cristianismo en relación con una conciencia humana moralmente comprometida e históricamente situada. (p. 344)

Por ello, la teología fundamental trata de pensar cómo el dato revelado impacta la vida histórica del creyente. La dimensión de historicidad es imprescindible en el momento de pensar cuál es la dimensión dialógica de la misma teología. Y porque aparece la cuestión de la libertad el cristianismo no puede continuar apelando a una demostratio excesivamente racionalista y apriorística. Solo desde la crítica, el diálogo y la comprensión antropológica de la revelación, el cristianismo podrá hacer dialogar su propuesta de sentido en el pluriforme espacio público actual. Esto, en definitiva, debe constituir "la orientación funcional de la teología" (Geffré, 1969, p. 347), es decir, si la teología quiere presentarse como culturalmente válida, debe comenzar desde el ser humano y desde sus múltiples experiencias de Dios en cuanto Dios ha querido comunicarse, dialogar y encontrarse con ese mismo ser humano en una historia concreta. Es, por tanto, apelar al fundamento de 
una antropología trascendental ${ }^{4}$ y de una teología fundamental contextual ${ }^{5}$ como posibilidades de pensar la función dialogal de toda teología, a la vez que "la teología contemporánea se preocupará más bien de manifestar la significación que el misterio cristiano en su conjunto tiene para el hombre" (p. 347).

En vista de ello, Waldenfels (1994) reconoce que el fin último de la teología es intentar "crear una comunicación y una comunidad de comunicación al servicio de la promesa divina de salvación a la humanidad por medio de Jesucristo" (p. 85). La importancia comunicacional de la teología no se basa - exclusivamenteen la transmisión de un conjunto de doctrinas. Eso sería quedarse centrado en el concepto intelectualista y jurídico de revelación. ¿Qué es lo que comunica la teología? Es a la misma persona de Jesucristo, quien es su centro y centro de toda la historia del mundo, a la vez que espacio de comprensión del misterio mismo del ser humano (cfr. Pablo, 1965, n. 22) ${ }^{6}$. De esta dimensión dialógica y comunicativa de la teología que sabe colocar a Jesucristo al centro, surge también la importancia de descentrar a la Iglesia y a la teología, es decir, evitar la falsa comprensión

4 Aquí estamos asumiendo el modelo teológico ofrecido por Karl Rahner en cuanto a la consideración de que el ser humano es espíritu abierto a una posible Revelación-Palabra (incluso silencio) de Dios en la historia como único lugar posible de acceder a esta interpelación. En el ser humano, existe el llamado existencial sobrenatural que capacita al ser humano oyente para acoger o rechazar al Dios que llama. Müller (2009) asume este método antropológico trascendental hablando del "horizonte trascendental de toda antropología" en los siguientes términos: "el hombre es un ser condicionado por la historia, con experiencias básicas contrapuestas y concepciones radicalmente enfrentadas entre sí [...] solo se hace luz en la pregunta sobre qué es el hombre cuando se contempla su relación a un origen trascendental y a un fin que supera el universo creado" (p. 107).

5 Waldenfels (1994) acunó el concepto de teología fundamental contextual para responder a la pregunta de cómo hacer teología atendiendo al contexto particular de la cultura en la que se ubica. No es lo mismo hacer teología en América Latina, Europa o Asia, no es lo mismo una teología hecha por mujeres, por grupos LGTBI, por sacerdotes o migrantes. Hay sensibilidades teológicas particulares que deben ser puestas en diálogo con el contexto. Sostiene este autor que la teología debe abarcar una pluralidad de temáticas. "el ser humano como posibilidad de oír la palabra; la pluralidad de lenguas, culturas, situaciones sociales como desafíos al cristianismo para su asimilación; los obstáculos a la comprensión; el papel de lo negativo en el mundo; las experiencias de perdición y la exigencia de salvación y de sentido; la competencia en las ofertas de sentido y de salvación" (p. 75).

6 Silva (2017) reconoce que el supuesto de que el cristianismo es un conjunto de verdades es erróneo. El cristianismo no es un credo. Por ello, sostiene que "lo que la Iglesia debe comunicar al mundo no es en primer lugar una doctrina sino la persona misma de Jesús; la doctrina y el Credo juegan un papel secundario, aunque importante para evitar las concepciones equivocadas acerca de Jesús. Dicho de otro modo, la confesión de la verdad doctrinal sin el encuentro personal con Jesús (y, en Él, con la fuente última de su vida, su Padre Dios) es inútil, porque no salva; lo que nos salva es el encuentro personal con Jesús" (p. 162). 
de que la Iglesia es el centro de la historia de la salvación. De un eclesiocentrismo hemos de pasar renovadamente al cristocentrismo.

Esta dinámica comunicacional para Waldenfels (1994) se logra a través de tres situaciones o formas concretas en las que la teología se articula como diálogo en sus nuevas exigencias y formas de evangelización. Ellas son "la apologética, la hermenéutica y la dialógica" (p. 85). La primera ya fue revisada someramente cuando nos hacíamos eco de las palabras de Geffré (1969), en las que se destaca que ella siempre ha estado presente en la historia de la Iglesia, basada en dar razón de nuestra esperanza a través del testimonio de esa esperanza en nuestra forma concreta de vida. La hermenéutica, por su parte, busca la comprensión de la incomprensión del mensaje cristiano a partir de una adecuada interpretación tanto de los hechos como de las palabras, reconociendo que nos interpela un lector.

Finalmente, la dimensión dialógica que se articula contra el desinterés. Waldenfels (1994) sostiene que toda estructura comunicativa o de diálogo tiene la característica de ser triádica: relación de un yo con un tú, encuentro del yo con el tú en la cosa y la autorrelación en cuanto la relación del tú se reinvierte en el yo. En esta situación, Waldenfels sostiene que dos cuestiones son centrales en la teología, a saber, que el sujeto de la teología son los mismos seres humanos y que al no ser objetos deben ser tratados como sujetos los destinatarios del anuncio de la fe y del diálogo teológico. De estas indicaciones, surgen finalmente dos consecuencias que pueden ser entendidas en un nivel práctico o pastoral: diálogo y misión y diálogo como solidaridad. En la primera situación, se refuerzan las dimensiones colegiales y sinodales de la Iglesia, las relaciones de la Iglesia con el mundo, el lugar de las Iglesias locales y el reconocimiento de la pluralidad de los grupos que conviven con la Iglesia. Y en el segundo nivel - diálogo como solidaridad - es el reconocimiento de la solidaridad en las dinámicas de diferencia y no de uniformidad. Aquí Waldenfels reconoce el escándalo entre las desigualdades de las Iglesias del sur y del norte, la lucha histórica de los desfavorecidos ante la que el cristianismo no puede permanecer neutral.

Quisiéramos detenernos brevemente en la primera consecuencia expuesta por el teólogo de Bonn. En este tiempo de auténtica crisis en la Iglesia católica, sobre todo en la experiencia chilena (de la cual soy hijo), por el liderazgo y el poder ejercido por los obispos y sacerdotes, por la crisis de credibilidad y confianza, así como por las cuestiones concernientes a la transmisión de la fe, consideramos que la vivencia del diálogo como puesta en marcha de una nueva sinodalidad es una tarea más que necesaria. La sinodalidad, entendida como puesta en común de situaciones de importancia general, debe pasar por el reconocimiento de la experiencia de los creyentes, el sensus fidei, de un diálogo cercano con la autoridad 
eclesial, de un reconocimiento del ethos cultural que rodea a dicha comunidad y de una nueva lectura de la historia a la luz de la Palabra de Dios. La función del diálogo en la teología debe percibir que nuestra disciplina está en la frontera, reconociendo cómo Dios también está en esa frontera. La teología debe constituirse, en este tiempo, en profecía del Espíritu, actitud de caridad y dinámica de fe. Solo desde estas cuestiones prácticas y cotidianas la función dialogal de la teología en vista de una cultura del encuentro podrá responder a las exigencias de la hora presente.

\subsection{El diálogo como una nueva actitud y sensibilidad de época: el Concilio Vaticano II}

La conciencia teológica contemporánea, y en virtud de la puesta al día y del retorno a las fuentes del Vaticano II, asumió decididamente un giro vital hacia el diálogo como condición de un nuevo tiempo en la transmisión del Evangelio. Antes señalábamos que el diálogo, aunque presente en los testimonios bíblicos como fuente para conocer la revelación, no era una actitud obvia en la vida de la Iglesia. Fue gracias al Vaticano II donde la Iglesia, y mirando al mundo, hace una opción decidida de pensarse en el mundo, participando de la historia, acogiendo lo positivo de las culturas y de los nuevos lenguajes. Al decir de Renato Hasche (“En las fronteras del diálogo" edita teólogo U. del Norte, 1984):

El diálogo fue un término que se usó mucho en tiempos del Concilio

Vaticano II. Era la época del encuentro de la Iglesia católica con las iglesias protestantes y con la Iglesia ortodoxa de Oriente. También era la apertura de una Iglesia doctrinalmente monolítica a los nuevos planteos de la cultura actual, de la situación sociológica y de la técnica. (p. 7)

Este es, por tanto, el comienzo de la experiencia del diálogo entendido como nueva actitud y sensibilidad de época, incluso como "signo de los tiempos" al entender de Girardi (1971) a la vez que como "uno de los aspectos más impresionantes y discutidos del nuevo estilo de la Iglesia católica" (p. 251).

El diálogo aparecerá con renovada fuerza en la constitución pastoral Gaudium et spes. El diálogo "Iglesia y mundo" se concretiza en nuevas formas. En el documento que surge a partir del llamado Esquema XIII, ${ }^{7}$ se articulará desde

7 Sostiene Silva (2016) que "la función dialogal - que algunos han llamado también fronteriza - se hace plenamente consciente en el Concilio Vaticano II, que pone término oficial al largo periodo de enfrentamiento de la Iglesia católica con la modernidad y favorece una nueva 
el método de ver, juzgar y actuar: vemos el mundo, lo juzgamos desde la fe en diálogo con las ciencias humanas y sociales, y actuamos en vista de su transformación. El nacimiento de una nueva era, de una cultura constitutivamente plural, con el surgimiento de otras ofertas de sentido, con la presencia del ateísmo y del progreso tecnológico, incluso con el nacimiento de nuevas categorías y expresiones lingüísticas, debe posicionar al creyente en diálogo con estas realidades. La teología, si quiere ser fiel a su misión de evangelización en cada contexto, no puede abandonar la lógica del diálogo.

Si los cristianos creemos que Dios actúa objetivamente en la historia, hemos de ejercitarnos en el discernimiento de los signos de los tiempos (cfr. Pablo, 1965, nn. 4, 11,44) de manera de escuchar las esperanzas, las alegrías, las tristezas y los anhelos de todos los hombres y las mujeres, sobre todo de los más pobres (n. 1). Houtart (1965) sentencia:

La toma de posición de los cristianos respecto a una cuestión tan fundamental como el diálogo no puede efectuarse sin hacer referencia a las grandes esperanzas y las grandes zozobras que aquejan a la humanidad. El diálogo se establecerá sobre esta base o no se hará. (p. 16)

Con Houtart (1965) interpretamos que el diálogo es la condición de posibilidad para encontrarse en la diferencia. El diálogo es la base en un nuevo tiempo de evangelización. La Iglesia tuvo que aprender a dejar de lado el anatema que dominó hasta el Vaticano I y aprender a construir una renovada gramática del diálogo.

Lo interesante del giro del Vaticano II en relación con el caso específico del diálogo es que "este espíritu no es un fenómeno puramente interno de la Iglesia católica. Es el resultado de una evolución de conjunto de la conciencia cristiana, y de una manera general de la conciencia humana contemporánea" (Girardi, 1971, p. 251). Con el Concilio, la Iglesia debió aprender a caminar junto con la historia, comprendiéndose dentro de ella. Para entender más aún este nuevo espíritu y actitud, recuperemos el número 44 de Gaudium et spes, que es como el manifiesto eclesial de reconocimiento de las cuestiones positivas del mundo contemporáneo:

Interesa al mundo reconocer a la Iglesia como realidad social y fermento de la historia. De igual manera, la Iglesia reconoce los muchos

actitud de diálogo con la cultura moderna y con las ciencias desarrolladas en ella. Influyen especialmente los debates en torno al famoso "Esquema 13" que había de dar origen a la Constitución Pastoral Gaudium et spes sobre la Iglesia en el mundo moderno. El Concilio afirma que la Iglesia debe dialogar con el mundo actual; lo que trae lógicamente consigo que, al interior de la Iglesia, el diálogo debe ser emprendido también por la teología; a su vez, la teología fundamental debe reflexionar sobre esta dimensión dialogal de la teología y de la Iglesia" (pp. 192-193). 
beneficios que ha recibido de la evolución histórica del género humano. La experiencia del pasado, el progreso científico, los tesoros escondidos en las diversas culturas, permiten conocer más a fondo la naturaleza humana, abren nuevos caminos para la verdad y aprovechan también a la Iglesia. Esta, desde el comienzo de su historia, aprendió a expresar el mensaje cristiano con los conceptos y en la lengua de cada pueblo y procuró ilustrarlo además con el saber filosófico. Procedió así a fin de adaptar el Evangelio a nivel del saber popular y a las exigencias de los sabios en tanto era posible. Esta adaptación de la predicación de la palabra revelada debe mantenerse como ley de toda la evangelización. Porque así en todos los pueblos se hace posible expresar el mensaje cristiano de modo apropiado a cada uno de ellos y al mismo tiempo se fomenta un vivo intercambio entre la Iglesia y las diversas culturas. (Pablo, 1965)

Esta es la clave interpretativa para asumir cómo el diálogo ha entrado en la dinámica misma de la teología. Consciente de los beneficios que recibe de las culturas y del lenguaje, agradecida de los tesoros de la cultura, sobre todo de la cultura popular, la teología es capaz de adaptar la predicación de la palabra revelada en los distintos contextos. Con ello, comprendemos cabalmente a qué hacemos referencia con que el diálogo es la condición de posibilidad de una cultura del encuentro. En el Vaticano II, la Iglesia realizó un ejercicio de escucha y de hacer silencio, primera condición del diálogo; de reconocimiento del interlocutor, a saber, el mundo, segunda condición; de comprender cuál era su mensaje y su historia como tercera condición; y de entrar en diálogo, apertura y encuentro con él como resultado consecuente de los anteriores requisitos, encuentro que se actualiza sin imposición de doctrinas, sino como invitación a un encuentro con Dios, del que la Iglesia es medio y testigo, no fin en sí misma.

Esta es la manera a través de la que el mensaje se puede transmitir de un modo apropiado. En palabras de Girardi (1971):

Consciente [la Iglesia] de la multiplicidad de culturas, de ideologías, de religiones, que solicitan todas ellas el asentimiento de los hombres, inclinado a no excomulgar a nadie, se ve inducido a considerar su apropia orientación mental como una elección doctrinal, que tiene que pasar por una confrontación leal con otros puntos de vista. La apertura a los demás, que se expresa en el diálogo, es una nueva expresión de este espíritu crítico. (p. 252) 


\section{Algunas cuestiones actuales en torno al diálogo y a la cultura del encuentro}

Al finalizar nuestra propuesta, quisiéramos pensar algunas cuestiones actuales y pertinentes en torno al diálogo como condición de posibilidad para vivir la cultura del diálogo, con un especial interés en Evangelii gaudium, entendido como un caso particular de recepción del espíritu y de la sensibilidad del diálogo, como experiencia cristiana y como actitud de la nueva cultura humana. En el capítulo IV de Evangelii gaudium, encontramos el apartado IV titulado "El diálogo social como contribución a la paz" (nn. 238-258). Francisco reconoce cinco formas concretas de diálogo: a) diálogo entre la fe, la razón y las ciencias; b) diálogo ecuménico; c) relaciones con el judaísmo; d) diálogo interreligioso; y e) diálogo social en un contexto de libertad religiosa. A efectos de este estudio, vamos a recuperar solo el diálogo social en un contexto de libertad y de pluralidad religiosa como el que nos constituye.

En primer lugar, Francisco (2013) recuerda que los padres sinodales del Sínodo sobre la Evangelización celebrado en 2012 "recordaron la importancia del respeto a la libertad religiosa, considerada como un derecho humano fundamental" (n. 255). En el contexto chileno, fue el 14 de octubre de 1999 cuando en el Diario Oficial fue publicada la Ley 19.638 conocida como ley de cultos, "cuyo texto estableció normas reguladoras de la constitución jurídica de las iglesias y organizaciones religiosas, conducentes a la obtención de una personalidad jurídica de Derecho público, previa inclusión de las entidades en un registro estatal público" (Del Picó, 2010, p. 1). Con esta promulgación, comienza un nuevo tiempo en la "profundización de los derechos fundamentales" (p. 1). El diálogo social en la libertad de creencias está, por tanto, asegurado a nivel jurídico como parte integradora de los derechos humanos. Por tanto, este es un espacio mínimo para ejercitar el diálogo común a todos.

Esto viene a asegurar para Francisco (2013) "un sano pluralismo, que de verdad respete a los diferentes y los valore como tales" (n. 255). La pluralidad de relaciones, el multiforme rostro de los pueblos y de las culturas, constituye a nuestro entender la experiencia que permite comprender cómo el diálogo es la condición de posibilidad para ejercitar la cultura del encuentro. Reconocer la presencia de nuevas ofertas de sentido, de los nuevos movimientos religiosos, del aumento del pentecostalismo en América Latina y de otras expresiones religiosas convoca a que nuestra teología que busca entender estas experiencias cotidianas se abra decididamente al diálogo que convoca a la tolerancia, el respeto y la paz. 
La pluralidad de experiencias religiosas se concretiza a su vez en la presencia que las religiones tienen en el espacio público. Francisco (2013) también habla de ella (n. 256), y se propone distinguir cuáles son las formas en las que se vive la incidencia pública de la opción religiosa. Para vivir adecuadamente la religión en lo público, Francisco sostiene que es necesario detectar cuáles son las búsquedas de "la verdad, la bondad y la belleza, que para nosotros tienen su máxima expresión y su fuente en Dios. Los percibimos como preciosos aliados en el empeño por la defensa de la dignidad humana, en la construcción de una convivencia pacífica entre los pueblos y en la custodia de lo creado" (n. 257). Francisco, en su lógica del diálogo como espacio de construcción de la paz social y de la cultura del encuentro, está favoreciendo un pacto social pero que se supera a sí mismo. Francisco, a juicio de Domingo (2014), concede importancia al Estado desde los principios de subsidiariedad y solidaridad (p. 124).

Francisco, además, es consciente de que el diálogo que ejerce la Iglesia no tiene soluciones para cuestiones particulares, y por ello él considera que el diálogo debe ejercitarse en común con otras propuestas humanas, religiosas, políticas, culturales. Hay, por tanto, una interdisciplinariedad e interresponsabilidad en la construcción social del diálogo. Domingo (2014) sostiene:

Esta cultura del diálogo se traslada también a las relaciones con otras confesiones, al ámbito de la razón y las ciencias. La razón tampoco es patrimonio de algunos científicos que se exceden en sus juicios o se extralimitan en sus afirmaciones. En ese caso, más que ante la razón, estamos ante una determinada ideología que cierra el camino para el diálogo. (p. 124)

¿En qué momento el diálogo se traslada a una conveniente ideología? ¿En qué límite se separa la cultura del diálogo con la cultura de los acuerdos establecidos por unos pocos y para unos pocos? ¿Cuándo la razón se transforma en pretexto para establecer otras lógicas articuladas no en la gramática del diálogo, sino en la gramática de la autoridad despótica? Incluso, y pensando en la común responsabilidad del diálogo, pensar en cómo la confianza es una condición para la misma comunicación. No una confianza ingenua, sino un acercamiento crítico, reflexivo, que escuche, que favorezca una nueva reflexión. Pareciera que por esta vía se puede lograr una verdadera cultura del encuentro.

Un último elemento que considera Francisco (2013) en el momento de pensar el diálogo en medio de la libertad de creencias es el establecimiento de los llamados "atrios de los gentiles, donde creyentes y no creyentes puedan dialogar sobre los temas fundamentales de la ética, el arte y de la ciencia, y sobre la 
búsqueda de la trascendencia. Este también es un camino de paz para nuestro mundo herido" (n. 257). En este nuevo contexto sociopolítico, ecológico, de género, educativo, antropológico y religioso, la teología debe asumirse como un espacio que, a través de su función comunicativa, pueda contribuir, en comunión con otras ciencias y disciplinas, a sanar el mundo herido. Para ello, la fe cristiana debe evitar la comprensión que habíamos señalado, a saber, la falsa comprensión de que es la única posible respuesta por el sentido humano. La voz cristiana articulada en la reflexión teológica deberá promover nuevas prácticas de diálogo a la altura de los tiempos.

Francisco, como caso particular de una auténtica recepción del Concilio Vaticano II y de su espíritu del diálogo, ha comenzado a imprimir este mismo espíritu en su pontificado. Para Kasper (2015), a Francisco

no solo le interesa el diálogo sobre las tradiciones culturales y religiosas tanto comunes como diversas, sino también la contribución común al bienestar de los pobres, los débiles y las personas sufrientes, el servicio común a la justicia, la reconciliación y la paz, el diálogo en vista de "mantener viva en el mundo la sed de lo absoluto" (Discurso a los representantes de las Iglesias y comunidades eclesiales y de las diversas religiones, 20 de marzo de 2013). (p. 96)

Estos espacios son los que mantienen viva la cultura, que no es patrimonio de unos pocos, sino que es el alma de un pueblo. Un pueblo solo se conforma a partir de la cultura del encuentro (cfr. Francisco, 2013, n. 220), reconociéndose como poliedro y no como esfera. La cultura del encuentro es así una cuestión policéntrica, intercultural y abierta a nuevas formas de relaciones. $\mathrm{Y}$, por ello, y frente a una experiencia dialógica intercultural, es necesaria una teología que sea dialógicamente intercultural, que sea espacio de encuentro, reciprocidad, reconocimiento y apertura al bienestar. Solo desde estas claves podremos estar en posibilidades de construir entre todos una auténtica cultura del encuentro, a imagen del Dios que en Jesús ha querido encontrarse con cada uno de nosotros en nuestra historia y en nuestra pluralidad de culturas. 


\section{Referencias}

Asensio, J. M. (2004). Una educación para el diálogo. Madrid, España: Paidós.

Benedicto XVI (2005). Deus caritas est. Recuperado de http://w2.vatican.va/content/ benedict-xvi/es/encyclicals/documents/hf_ben-xvi_enc_20051225_deus-caritasest.html

Benjamin, W. (1991). Para una crítica de la violencia y otros ensayos. Madrid, España: Taurus.

Del Picó, J. (2010). Presentación. En J. del Picó (coord.), Derecho de la libertad de creencias (pp. 1-2). Santiago de Chile, Chile: Abeledo Perrot.

Domingo Moratalla, A. (2014). Democracia y caridad: horizontes éticos para la donación y la responsabilidad. Santander, España: Sal Terrae.

Francisco (2013). Evangelii gaudium. Recuperado de http://w2.vatican.va/content/ francesco/es/apost_exhortations/documents/papa-francesco_esortazioneap_20131124_evangelii-gaudium.html

Geffré, C. (1969). Historia reciente de la teología fundamental: intento de interpretación. Concilium, 46, 337-358.

Girardi, J. (1971, agosto 10). Diálogo, revolución y ateísmo. Salamanca, España: Sígueme. “En las fronteras del diálogo" edita teólogo U. del Norte (1984). La Estrella del Loa, p. 2.

Houtart, F. (1965). La Iglesia y el mundo: Esquema XIII. Madrid: España: Nova Terra.

Heidegger, M. (2000). La carta sobre el humanismo (H. Cortés y A. Leyte, trads.). Madrid, España: Alianza.

Kasper, W. (2015). El papa Francisco: revolución de la ternura y el amor. Santander, España: Sal Terrae.

Maturana, H. (1999). Transformación en la convivencia. Santiago de Chile, Chile: Dolmen.

Müller, G. (2009). Dogmática: teoría y práctica de la teología. Barcelona, España: Herder.

Pablo VI (1965). Gaudium et spes. Recuperado de http://www.vatican.va/archive/ hist_councils/ii_vatican_council/documents/vat-ii_const_19651207_gaudium-etspes_sp.html

Ramírez, A. (2015). El lenguaje en la revelación: performatividad y pragmática. Theologica Xaveriana, 65(180), 301-325. doi: 10.11144/javeriana.tx65-180.1rpp

Scannone, J. C. (2017). Teología del pueblo. Santander, España: Sal Terrae.

Silva, S. (2016). La teología latinoamericana de la liberación en sus inicios: un intento de comprensión. Anales de la Facultad de Teología, 66(107), 192-193.

Silva, S. (2017). Temas de teología fundamental. Santiago de Chile, Chile.

Waldenfels, B. (1994). Antwortregister. Frankfurt am Main: Suhrkamp.

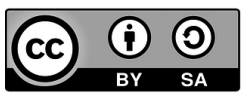

